\title{
How do we utilize risk scores to improve patient outcomes?
}

\author{
Bryan A. Whitson, MD, PhD

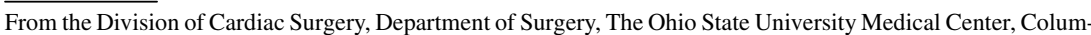 \\ bus, Ohio. \\ Disclosures: Author has nothing to disclose with regard to commercial support. \\ Received for publication Jan 1, 2016; accepted for publication Jan 5, 2016. \\ Address for reprints: Bryan A. Whitson, MD, PhD, Director, End-Stage Cardiopulmonary Failure Program, Co- \\ Director, COPPER Laboratory, Division of Cardiac Surgery, Department of Surgery, The Ohio State University \\ Medical Center, N-816 Doan Hall, 410 W 10th Ave, Columbus, OH 43210 (E-mail: bryan.whitson@osumc. \\ edu). \\ J Thorac Cardiovasc Surg 2016;151:1422-3 \\ $0022-5223 / \$ 36.00$

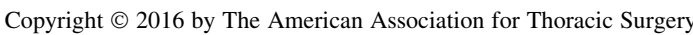 \\ http://dx.doi.org/10.1016/j.jtcvs.2016.01.007
}

Through the years, pneumonia has been termed "the old man's friend" due to its insidious onset and poor prognosis. The onset of pneumonia in the perioperative period, either preceding cardiac surgery ${ }^{1}$ or after, ${ }^{2}$ is every bit as ominous. The onset of pneumonia after major cardiac surgery significantly contributes to increased morbidity, mortality, and intensive care unit (ICU) length of stay.

In this month's issue of JTCVS, Dr Arman Kilic and colleagues ${ }^{3}$ present their work on the development of a scoring system to estimate the risk of developing pneumonia after cardiac surgery. In the analysis by Kilic et al, ${ }^{3}$ investigating a single-institution data set that was split into a training and validation set developed a 33-point scoring system. From this analysis, we are given 6 factors that can be used to predict postoperative pneumonia: age, chronic lung disease, peripheral vascular disease, cardiopulmonary bypass time, intraoperative transfusion, and the need for an intra-aortic balloon pump.

Although the current analysis is thorough and robust, and the scoring system unique, many of the significant contributing factors to the risk of pneumonia are not surprising. Of the numerous articles in the literature on postoperative pneumonia, the 4 articles referenced in this commentary can be intertwined with the current study to lead us to a point of using these data to improve patient outcomes.

In a comprehensive meta-analysis of 11 studies and 10,708 patients performed by He et $\mathrm{al}^{2}$ published in JTCVS in 2014, 12 contributing factors were identified. Of those factors identified, the most notable were the presence of end-organ failure/dysfunction, emergency operation, intra-aortic balloon pump use, cardiopulmonary bypass and cross-clamp time, and duration of mechanical ventilation and need for reintubation. The incidence of ventilator-associated pneumonias (VAP) was 21.7/1000 patient-ventilator days, with an overall incidence of $6.4 \%$; however, if patients were ventilated more than 48 hours, the rate increased to $35.2 \%$. Those who developed VAP had a $15 \%$ higher odds ratio of mortality: clearly postoperative pneumonia increases the risk of mortality.

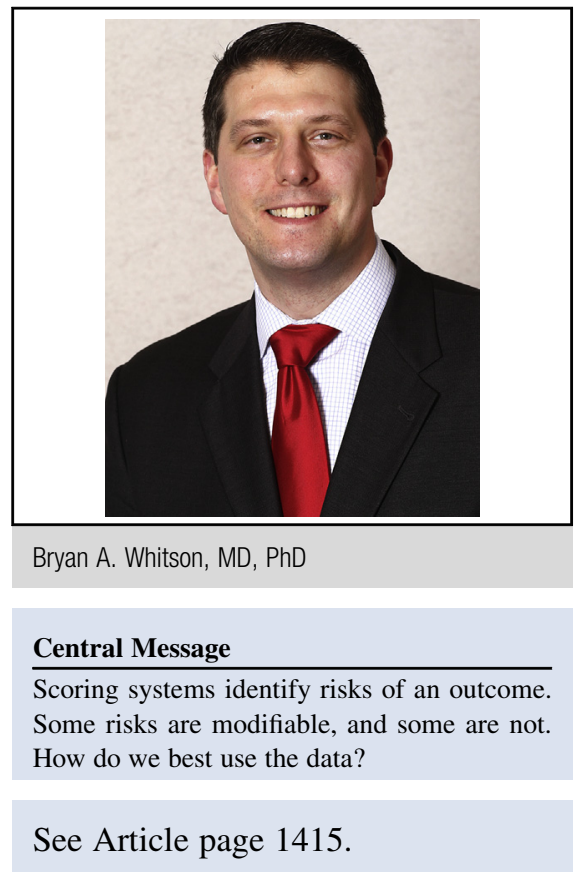

The remaining 3 articles are more concise. In the single-institution analysis performed by Allou and colleagues ${ }^{4}$ (which is similar in methodology and identification of risk factors but not scoring system development to the current study), 4 items were identified as risks for postoperative pneumonia: age, chronic obstructive pulmonary disease, ejection fraction, and a combined metric of blood transfusion and cardiopulmonary bypass duration. Likosky and colleagues ${ }^{5}$ queried 16,182 patients after coronary bypass grafting in the Michigan Society of Thoracic and Cardiovascular Surgeons Quality Collaborative and found a transfusion-volume-dependent interaction with the rate of pneumonia. Last, Halpin and colleagues $^{6}$ from the Inova group investigated factors contributing to pneumonia incidence in their cardiac ICU before and after initiation of aggressive VAP care bundles. In their analysis, emergent intubations, reintubations, and blood transfusions were associated with increased rates of pneumonia, despite the initiation of aggressive, modern ICU nursing/respiratory therapy care and VAP bundles. ${ }^{6}$

Although these studies are representative and all address unique perspectives to the pneumonia problem, there begin to appear to be repeating risk factors. To enact change that decreases pneumonia rates and improves overall outcomes, we must reduce these identified risks and scores into practice such that our behaviors change. 
Our charge as cardiothoracic surgeons then is to strive to minimize transfusion through meticulous technique and blood conservation strategies, to operate efficiency and proficiently, to potentially tailor or develop hybrid therapies to the very aged, and to make every effort not to perform emergency surgery, if possible. Some of this is self-evident, some risks are modifiable, and some are not.

We are ultimately left with how to interpret the data and use the scoring system most effectively. In the article by Kilic et al, ${ }^{3}$ Figure 1 demonstrates a nice relationship of score and risk, but at the full 33 points, the risk is only $59 \%$ and, as denoted in Figure 2, the highest-risk grouping with a score greater than 10 had a modest pneumonia rate of approximately $8 \%$. At that threshold, the risk of pneumonia, while potentially modifiable, would not seem prohibitive. Is there a threshold where risk would be considered too high to consider surgery? This is where we turn to sound surgical judgment and application of the data to guide us.

\section{References}

1. Shih T, Paone G, Theurer PF, McDonald D, Shahian DM, Prager RL. The Society of Thoracic Surgeons adult cardiac surgery database version 2.73: More is better Ann Thorac Surg. 2015;100:516-21.

2. He S, Chen B, Li W, Yan J, Chen L, Wang X, et al. Ventilator-associated pneumonia after cardiac surgery: A meta-analysis and systematic review. J Thorac Cardiovasc Surg. 2014;148:3148-55. e1-5.

3. Kilic A, Ohkuma R, Grimm JC, Magruder JT, Sussman M, Schneider EB, et al. A novel score to estimate the risk of pneumonia after cardiac surgery. J Thorac Cardiovasc Surg. 2016;151:1415-21.

4. Allou N, Bronchard R, Guglielminotti J, Dilly MP, Provenchere S, Lucet JC, et al Risk factors for postoperative pneumonia after cardiac surgery and development of a preoperative risk score*. Crit Care Med. 2014;42:1150-6.

5. Likosky DS, Paone G, Zhang M, Rogers MA, Harrington SD, Theurer PF, et al Red blood cell transfusions impact pneumonia rates after coronary artery bypass grafting. Ann Thorac Surg. 2015;100:794-800; discussion 801.

6. Halpin L, Henry L, Szelkowski L, Hunt S, Vourlekis J, Ad N. Ventilator-associated pneumonia among cardiac surgery patients: What can we do for prevention? $J$ Nurs Care Qual. 2013;28:345-51. 